\title{
Open Scholarship Practices Reshaping South Africa's Scholarly Publishing Roadmap
}

\section{Reggie Raju ${ }^{1, *}$, Jaya Raju ${ }^{2, \dagger}$, and Jill Claassen ${ }^{3, \dagger}$}

1 University of Cape Town Libraries, University of Cape Town, Chancellor Oppenheimer Library, Rondebosch 7701, South Africa

2 Library and Information Studies Centre, University of Cape Town, Rondebosch 7701, South Africa; E-Mail: jaya.raju@uct.ac.za

3 University of Cape Town Libraries, University of Cape Town, Chancellor Oppenheimer Library, Rondebosch 7701, South Africa; E-Mail: jill.claassen@uct.ac.za

$\dagger$ These authors contributed equally to this work.

* Author to whom correspondence should be addressed; E-Mail: reggie.raju@uct.ac.za; Tel.: +27-21-650-5827.

Academic Editor: Remedios Melero

Received: 6 October 2015 / Accepted: 27 November 2015 / Published: 8 December 2015

\begin{abstract}
South African higher education institutions are the largest producers of research output on the African continent. Given this status, South African researchers have a moral obligation to share their research output with the rest of the continent via a medium that minimizes challenges of access; open scholarship is that medium. The majority of South African higher education libraries provide an open access publishing service. However, in most of these cases this service is via engagement with the green open access route, that is, institutional repositories (IR). Some of the libraries have piloted and adopted gold open access services such as publishing of "diamond" gold open access journals and supporting article processing charges. The experiment with publishing open monographs is a new venture. This venture must be viewed against the backdrop of the need for open educational resources (OERs). OER is an area that is very much in a fledgling stage and is gaining traction, albeit, at a slow pace. The growth of IRs, the growth in support for gold open access including the library acting as a publisher, the experimentation with open monographs, and OERs are all shaping South Africa's scholarly publishing roadmap.
\end{abstract}


Keywords: open scholarship; open access; OERs; South Africa; article processing charges; diamond open access

\section{Introduction}

Koen Becking of Tilburg University pronounced that "we are entering a new era in publications" [1]. The Dutch government strongly supports gold open access publishing and sets its sights on all publications by Dutch scientists being available through Open Access (OA) by 2024. This ambition is driven via universities, or the financiers of the research, paying for the research output to get published. According to the Dutch government, although there are costs incurred to get published, this is off-set by the elimination of subscriptions [1]. In this scenario, the significant positive is that the content is accessible to the widest possible reading audience.

This future model of publishing is juxtaposed against the traditional model of scholarly communication. In the traditional model, universities have subsidized much of the cost of scholarly publication by supporting researchers who contribute to the research papers and to the editorial and peer-review services. Publishers provide the less academic services, such as managing the peer-review process and the technical production and distribution of the research article. Universities, having already paid for the academic process, now have to pay for the technical process via high subscription costs. These journals are then made available to a broader institutional audience.

The technical services of publishers are paid for via a combination of page charges and subscription fees. The high subscription costs have the undesirable effect of limiting access to the research output. These high toll fees obstruct access to the output, limiting the scholarly value of the output and the visibility and impact of the researcher.

In both the traditional model and the future model, academic institutions are the financiers of the research publication. In the former, the significant beneficiary is the publisher (through large profit margins [2,3]) and the disenchanted are the reading audience (especially those from the developing world with limited access), the research output, and the researcher. In the future model, the disenchanted are commercial publishers and the beneficiaries are the reading audience through free access to the research output and the researcher via drastically improved visibility and concomitant impact.

Open access is the conduit for the transition from the traditional to the future model. Africa needs to get on this transformation bandwagon and convert its status from a net consumer of the world's knowledge production to a significant contributor of knowledge production. It is the contestation of the authors that free access to scholarly information, as per the future model, will help move Africa from the periphery of the world's knowledge production to the epicenter. Given that Africa produces only $0.7 \%$ of the world's knowledge production of which $70 \%$ is produced by South African researchers [4], these researchers have a moral obligation to freely share their scholarly output with the rest of the continent and the developing world.

Recognizing this moral obligation, this paper, firstly, briefly examines the changed higher education landscape in South Africa as the contribution of the respective institutions to OA is commensurate with 
the status of these institutions. However, before engaging in discussion on the changing research landscape and its contribution to OA, it is important to tease out the concept of open scholarship and the relationship between openness and OA on the one hand, and open educational resources (OERs) on the other. The focus of the discussion in this paper is the examination, from a South African perspective, of the growth of the green and gold routes to open access and, South Africa's engagement with OERs. In doing the latter, this paper draws from a questionnaire survey conducted on institutional repositories based in South African higher education libraries. It also draws, for this discussion, from the University of Cape Town's (where the authors are based) open access participation, and from the experiences of the authors within the South African higher education sector.

\section{The Three Pillars of Open Scholarship}

In South Africa, the concept of open access is often misinterpreted and there is some confusion between open scholarship and open access. The concept of open access is taken to be synonymous with open scholarship or openness. The concept of "openness" is much broader than open access. The openness movement or the open scholarship movement has three significant pillars of which one is open access and the other two are open source and open educational resources. However, the interdependent relationship fuels the misinterpretation. Nonetheless, the interdependent relationship between Open Source Software (OSS), OA, and OERs is critical for the growth of open scholarship [5].

The forerunner in the trilogy is open source which gained momentum using communities of practice and crowd sourcing as its golden threads. Open source refers to the creation of software in which the source code is available, free of charge, to the general public for use and/or modification from its original design. Open source code is typically created as a collaborative effort in which programmers improve upon the code and share the changes within the community. Open source was developed in the technology community as a counter to proprietary software owned by corporations [5].

The Open Source Software community has provided the necessary impetus for the rapid growth of the OA and OER movements. Examples of OSS that have significantly influenced the OA and OER movements include, amongst others, DSpace, Open Journal Systems, and Open Monograph Press. The growth of the OSS community has provided the OA and OER communities with software alternatives and options in terms of functionality [5].

Open access refers to free access to scholarly information for the end-user. The OA movement, in higher education libraries, gained momentum as a direct response to the subscription crisis, that is, the exponential increase in the cost of journal subscriptions on the back of decreasing library acquisition budgets. The founding philosophy of the movement was the sharing of scholarly literature for the furtherance of research. It is accepted that the primary purpose of dissemination of research is for the generation of new knowledge. The origins of OA were underpinned by a philanthropic philosophy, that is, sharing of research output for the benefit of society and the research community. However, the issue of improved visibility of research output began to gain prominence and began to overshadow the original philanthropic purpose. Publishers, recognizing the visibility imperative, constructed a new business model through article processing charges which met the demand for improved visibility [5]. 
The third segment in the trilogy is open educational resources. Open educational resources are teaching and learning materials that are in the public domain or have been released under an intellectual property license. OERs, by their very nature, mean that anyone can legally and freely copy, use, adapt, and re-share them. The founding philosophy of the OER movement was the improvement of the quality of education and the strengthening of the educational system, especially in the developing world [5].

As shown in Figure 1, a strong public education system increases the pipeline for growth of the research community: improved access to content contributes to an increase in research output. An output of a research process is new source code for new software and the cycle continues with the greatest beneficiary being society. Increased dissemination of the increased research output contributes to an increase in the information source pool to address the myriad of challenges that beset, for example, Africa and the developing world.

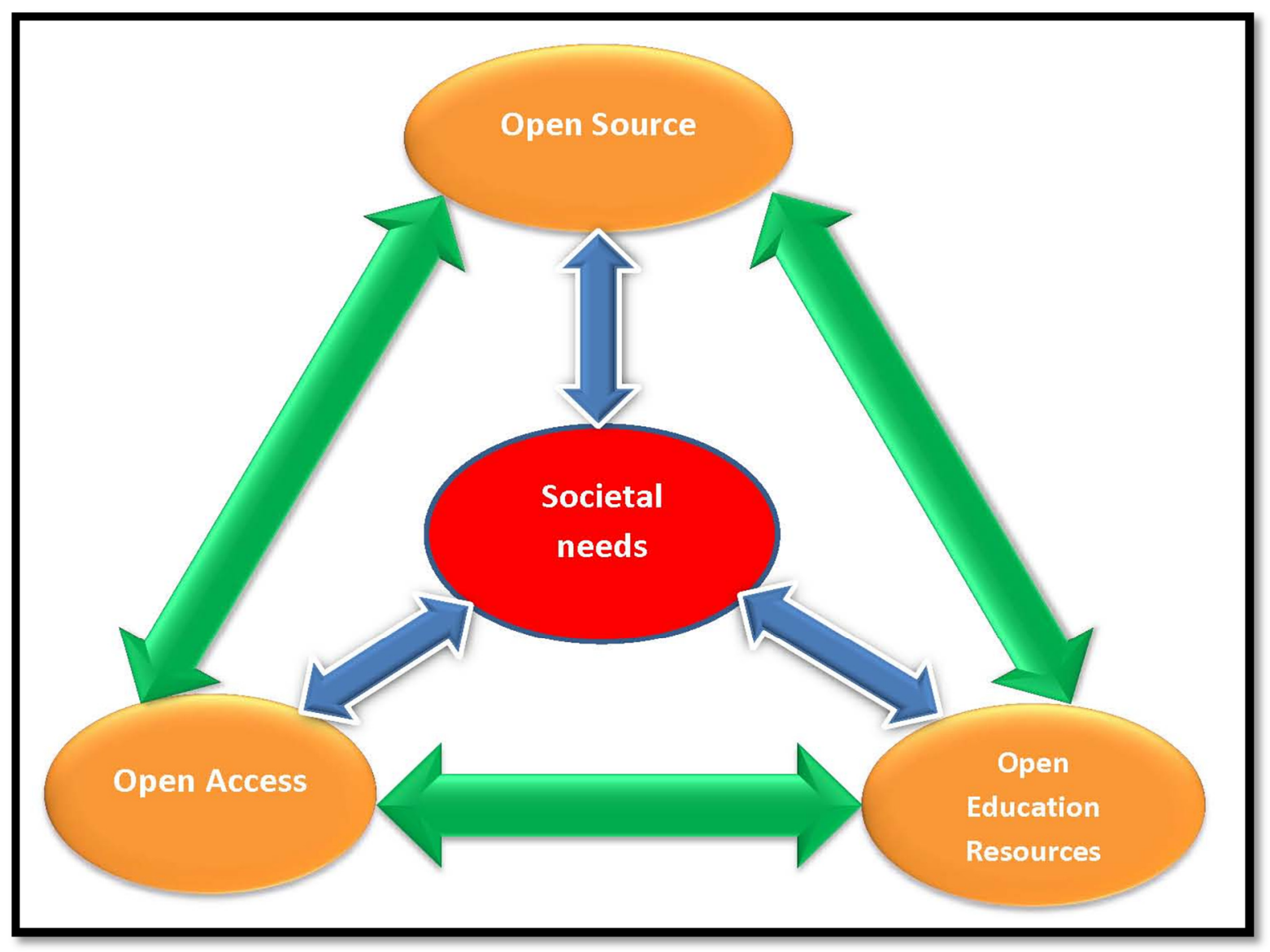

Figure 1. Societal benefits of open scholarship.

To demonstrate the impact that OA has on society, Shockey [6] cites the breakthrough that a high school student had with regard to diagnosis for pancreatic cancer. Shockey explains,

Andraka is a perfect example of the innovation that arises from unexpected places when anyone with curiosity, determination, and an Internet connection has open access to research articles-especially those reporting on publicly funded research. Open Access 
leads to innovation, which in turn can improve the lives of Americans and create critical new products and services-like Andraka's cancer diagnostic test.

As indicated earlier, the research output from South Africa is by far the highest on the continent [7]. Given the challenges that beset Africa, South Africa has a moral obligation to ensure that its research output is as accessible as possible to the widest African audience. By default, South Africa should take the lead in sharing its research output with the rest of the continent, the developing world and the world at large.

Within the South African higher education environment, according to a report published by De Villiers and Steyn in 2008 [8], ninety percent of the research output is produced by universities. The top five South African research institutions are Stellenbosch University, University of Cape Town, University of KwaZulu-Natal, University of Pretoria, and University of Witwatersrand [9]. Given the status of these institutions, it is expected that these top five research institutions would take the lead in OA and OER publishing as they have much research to offer the country and the continent.

\section{The South African Higher Education Landscape and Commitment to Open Access}

The South African higher education environment was re-landscaped in 2000 to re-dress, inter alia, an apartheid higher educational system [10,11]. In the re-landscaping process, the 36 public higher education institutions were reconfigured to create 23 institutions. In the last two years, three new universities were added but their contribution to research output is currently minimal as they are still establishing themselves.

Smaller universities and technikons (vocationally focused, technology oriented higher education institutions) were merged to form new entities, including traditional universities, universities of technology, and comprehensive universities. Six comprehensive universities were created to offer a combination of academic and vocational diplomas and degrees. The universities of technology (UoTs), of which there are six, focus on vocationally oriented education and offer, in the main, diplomas. The remaining 11 institutions are traditional universities offering theoretically oriented university degrees $[10,11]$.

It is against this backdrop that this paper examines OA in South Africa. The commitment to OA is, in many ways, influenced by the status of the institution. The academic remit of a UoT is to deliver vocationally oriented education, and hence the focus on research production, in most cases, is secondary. By default, their research output is relatively low. By the same token, there is high expectation of substantial research output from traditional universities, as one of the core functions of these institutions is research production. Comprehensive universities, on the other hand, are considered more "middle of the road" with commensurate expectation of research output. Given the core responsibilities, in terms of research output, associated with the different categories of institutions, there would be fair expectation from the traditional universities to invest substantially in open access for the sharing of research output. Table 1 provides a summary of South Africa's higher education institutions, their qualification offerings, and their teaching and learning and research foci.

The relatively strong culture of research production at traditional universities (also referred to as research intensive institutions) with their relatively strong information technology infrastructure, places them in an advantageous position of help South Africa shape the open scholarship roadmap. 
Table 1. South Africa's re-landscaped higher education system.

\begin{tabular}{ccc}
\hline No. of Institutions & Qualification Offerings & Expectations \\
\hline $\begin{array}{c}6 \text { universities of } \\
\text { technology (UoTs) }\end{array}$ & $\begin{array}{c}\text { Vocationally oriented } \\
\text { education-offer diplomas }\end{array}$ & $\begin{array}{c}\text { Focus on teaching and learning-research } \\
\text { production is secondary }\end{array}$ \\
\hline $\begin{array}{c}\text { comprehensive } \\
\text { universities }\end{array}$ & $\begin{array}{c}\text { Combination of academic and } \\
\text { vocational diplomas and degrees }\end{array}$ & $\begin{array}{c}\text { Focus on both teaching and learning and } \\
\text { research-expectation for research production is } \\
\text { higher than that of UoTs but lower than that of } \\
\text { traditional universities }\end{array}$ \\
\hline $\begin{array}{c}11 \text { traditional } \\
\text { universities }\end{array}$ & $\begin{array}{c}\text { Theoretically oriented } \\
\text { university degrees }\end{array}$ & A core function is research production \\
\hline
\end{tabular}

\section{Open Data}

Open access to scholarly information is dominated by published literature - be it via the green route, gold route or both. A latecomer to OA is open data which is important for the scientific publishing process as it ensures access to the underlying data of the published item [12]. Clobridge succinctly describes open data as data that is free to access, free to use, and free of most restrictions for reuse [13]. To promote reuse it becomes critical that good practices are adopted in order to make data accessible and findable to facilitate easy access and hence reuse. It is the librarian that is skilled to assist the researcher adopt these good practices.

Bertot et al. [14] submit that "librarians are relatively well-positioned in terms of existing skills to handle the implications of big and open data, as most of the long-term professional skills that have been cultivated by librarians - aggregating, cataloging, preserving, managing and curating information, as well as teaching digital literacy_are relevant to the challenges of big and open data" (p. 14). However, librarians and researchers in South Africa are grappling with the management of open data: there are no policies and strategies nor are there efficient implementation roll-outs. As indicated by Clobridge, major funders such as the Bill and Melinda Gates Foundation, the U.S. National Institutes of Health (NIH), the World Bank, and the Wellcome Trust have begun instituting open data policies and practices [13]. In South Africa, the National Research Foundation has "funding agreements" with fund holders for data management plans. However, there is no strategy or concerted compliance to ensure the efficient management of open data.

\section{Open Access to Scholarly Literature}

Open access publishing is dominated by two streams: the first is the institutional repositories stream and the second is publishing directly with an open access publisher. In terms of the former, this stream is commonly referred to as the "green route", with the significant objective of openly sharing research output of the institution. The second stream is generally referred to as the "gold road". In terms of the latter, South African higher education institutions are still in an experimental/piloting-to-teething phase. 


\subsection{Green Route: Institutional Repositories}

Institutional repositories (IRs) have been the forerunner of the open access movement. Lynch [15] points out that the "development of institutional repositories emerged as a new strategy that allows universities to apply serious, systematic leverage to accelerate changes taking place in scholarship and scholarly communication...". Lynch [15] defines institutional repositories as a set of services that a university offers to members of its community for the management and dissemination of its digitally created materials.

Like most other countries, South Africa adopted open access practices through the establishment of institutional repositories. South African university libraries, in the main, have taken responsibility for creating, populating and managing repositories. OA roles and responsibilities, for all intents and purposes, are becoming mainstreamed as an academic library service.

\subsubsection{Growth of Repositories}

Of the 23 established South African institutions of higher education, 19 institutions have institutional repositories. Figure 2 presents a graph from OpenDoar [16] that shows the growth of repositories in South Africa. There has been a steep incline from 2005 to 2010 - then there was a levelling out and then a resurgence from the middle of 2012 to the present (2015). This is an indication that repositories in South Africa are in the maturing phase. The fact that South African repositories are in a "maturing phase" coupled with the advantage of the country having a relatively strong research infrastructure with concomitantly high research output, places South Africa in the prime position of taking a leadership role on the continent in sharing research output.

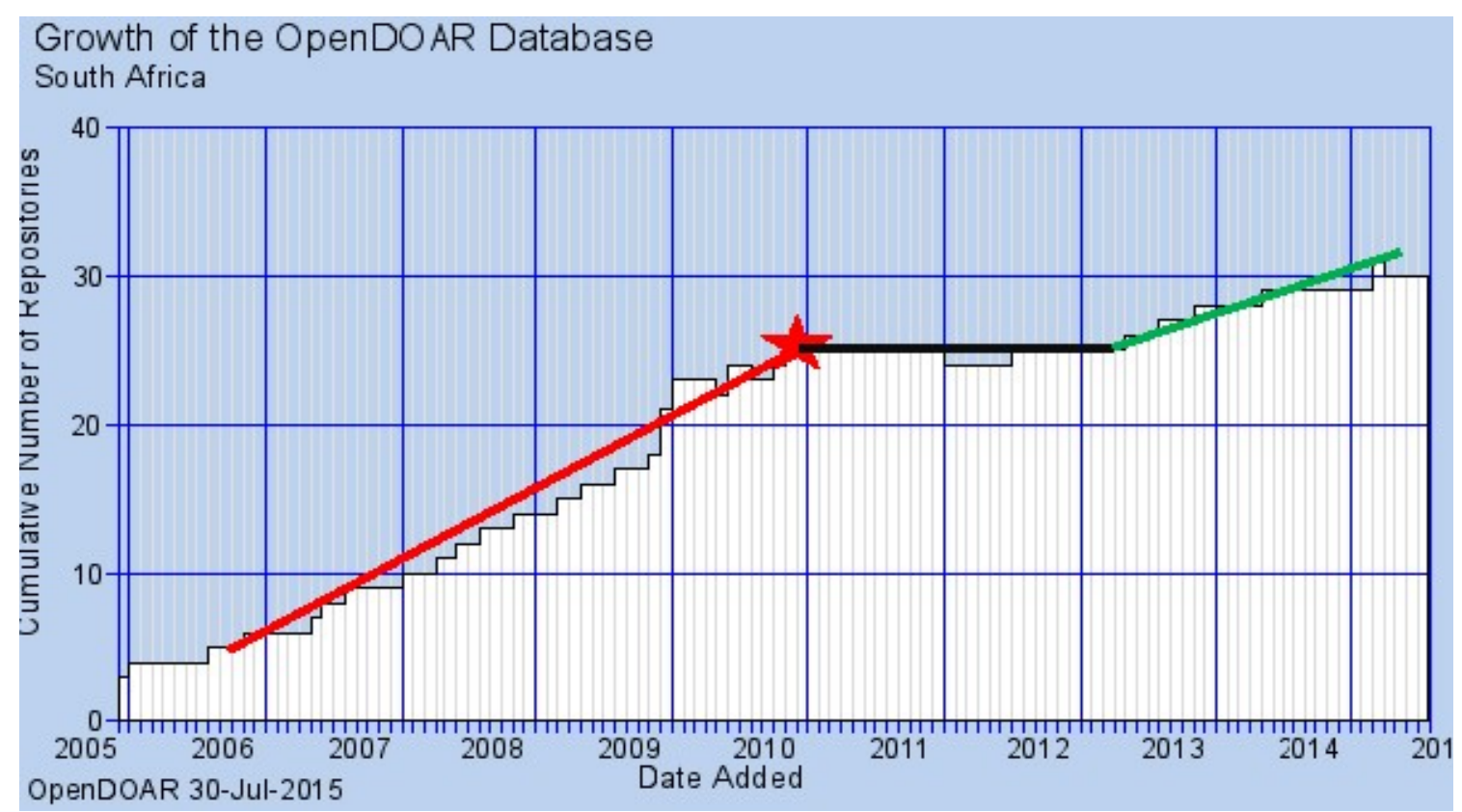

Figure 2. Growth of institutional repositories.

The authors infer from Figure 2 that the surge in the number of repositories, up to 2010, was influenced in some way by the hosting of the Berlin 2010 Open Access Conference in South Africa 
(Stellenbosch University). A number of higher education institutions in South Africa, leading up to the Conference, signed the Berlin Declaration on OA. The resurgence after the plateauing (as can be seen in Figure 2) is ascribed to the late adopters realizing the significance of OA.

\subsubsection{Institutional Contribution to Repositories}

The ingestion rate or the number of items in a repository is a reflection of the research output of the institution. A questionnaire survey of South African higher education institutions, undertaken by the authors in 2014, reveal the average number of items in the repositories of the three different types of higher education institutions in South Africa. Traditional universities have the highest average with 10012 items (50.4\%). Universities of Technology (UoTs) have a much lower submission rate (2326 items or 11.7\%). This is not surprising considering that their main focus is teaching and learning, as opposed to research production. It is evident from the number of items in the repositories that traditional universities are making major strides in sharing their research output. The average number of items in the repositories of comprehensive universities is 7530 items (37.9\%).

Further, closer examination of the data gathered via the questionnaire revealed that $64.2 \%$ of the total number of items in repositories in South Africa emanate from its five leading research intensive universities. One of these top five institutions has in its repository $37.5 \%$ of the total number of items in institutional repositories nationally. To re-iterate the issue, the leading research universities are making their output available via institutional repositories.

\subsubsection{Content in Repositories}

Given that repositories were built on the collection, organization, and dissemination of theses and dissertations, one would have assumed that all the repositories of higher education institutions in South Africa would have theses and dissertations as part of their collections (see Figure 3). However, there are two traditional universities and two UoTs that do not have theses and dissertations in their repositories. One can assume that these institutions are still paper-based (in terms of their theses and dissertations) and hence this output is not available in their repositories.

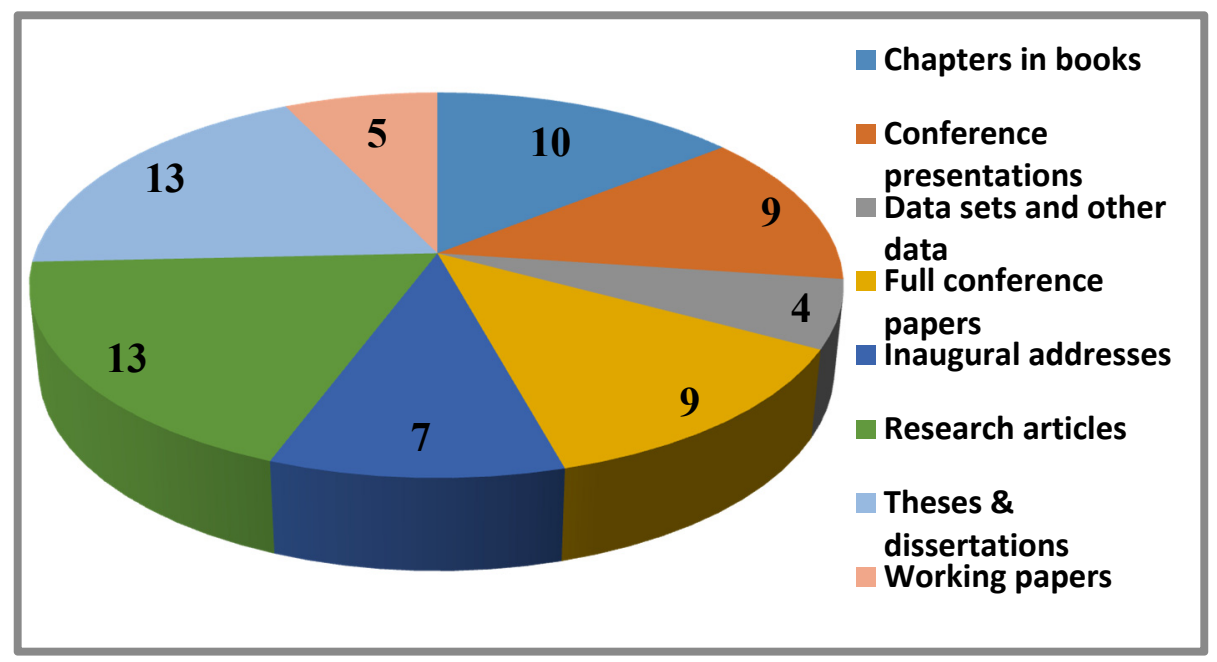

Figure 3. Type of content in IRs $(\mathbf{N}=\mathbf{2 3})$. 
It is interesting and encouraging to note the number of institutions that have research articles in their repositories. As indicated earlier, South Africa has a relatively strong research production culture and the sharing of this output with the rest of the country and the continent is an imperative. The hosting and preservation of other content types augurs well for the development of open access with the domino effect of improved usage and impact.

\subsection{Gold Route: Open Access Publishing}

As alluded to earlier, open access journals are electronic-based journals that make their published content available freely to all immediately upon publication. The business model associated with gold OA is based on end-users not being charged a fee to access the journal's content. However, the authors do pay article processing charges (APCs).

The open access journal publishing model, in the opinion of Crow [17], has turned the conventional commercial model for journal publication on its head. There are two streams in terms of this business model. The first stream is publishing with established "for profit" publishers, such as BioMed Central (BMC). Although the publisher, in terms of this model, makes the content free to the end-user, the primary objective of the publisher is to make a profit. The profit is generated, in the main, through the payment of article processing charges which are paid by the author or his/her academic institution or funding agency. In this business model, costs are incurred at the initial stages of the supply chain, instead of paying subscriptions at the end of the supply cycle; making the journal's content available online, free of charge [18,19].

The second stream is publishing with "not for profit" organizations, including organizations using open source software such as Open Journal Systems (OJS). The second stream is relatively new and is fast gaining momentum. In instances where there are no costs incurred by both the author and the end-user, such an instance is referred to by Fuchs and Sandoval ([20], p. 428) and Clobridge [21] as the "Diamond Open Access Model". In this model, not-for-profit and non-commercial organizations publish material that is made available totally free (free to read and free to publish).

Fuchs and Sandoval [20] go on to declare that this model makes academic knowledge a common good and reclaims the "common character of the academic system" (p. 428). Publication is "free of charge", including the fact that neither the authors nor their institutions have to pay publication fees, article processing charges or other fees for getting articles published.

At this point in time, some South African institutions of higher education are straddling both streams of the gold open access movement. According to the survey conducted in 2014, there are three higher education libraries in South Africa that have budgets for APCs; and there are four academic institutions that offer a diamond open access option.

\subsubsection{Article Processing Charges and Gold Open Access Publishing: A UCT Exemplar}

Taking its cue from the Dutch example on APCs, the Finch Report, and the fact that APCs are fast becoming mainstreamed in Europe with varying criteria, the University of Cape Town (UCT), in underwriting publishing in OA journals, instituted limited APC funding in 2012. With support from the University's Strategic Fund, this APC model was expanded in 2014. 
The UCT Open Access Journal Publication Fund has been established to support researchers with the publication of their research output in open access journals. The Fund was intended to contribute to APCs for submissions accepted for publication in open access journals or hybrid journals that have an open access option. The primary requirement of the Fund is that the journal has to be on South Africa's Department of Higher Education and Training (DHeT) list of accredited journals. Further, a copy of the publisher's version of the article must be submitted to the institutional repository (OpenUCT).

The support for APCs is located in the fact that there is evidence in the literature that supports the claim that increased access to publication contributes to increasing an institution's international profile [22,23]. Therefore, by supporting UCT authors to publish in OA journals, there will be improvement in the visibility, discoverability, and accessibility of research output of UCT. Further, the authors suggest that UCT's participation in OA processes will contribute to increasing access to its scholarship for developing country scientists.

\section{Rollout of Article Processing Charges}

The UCT Library received funding from the University's Strategic Fund, and added funding from the Library's acquisitions budget for the rollout of APCs. It was a calculated estimation that this amount, as a pilot project, would be sufficient for the first year of the roll-out. Despite the calculated estimation, funds were depleted just after mid-year, with a number of applications awaiting approval. There was a further request for funding from the Library's acquisition budget to fund requests for the rest of the year. To substantiate its request for additional funding, the Library did an assessment on the impact of the funding.

Assessment of the Impact of the Funding

Leading experts in the field of metrics analysis, Harnad and Brody [22] and Koler-Povh, Turk, and Južni [23], show that there is a correlation between downloads and impact and citations. They state that the time it takes, from the moment an article is accepted for publication (after peer review) to publication, for an article to be cited is anywhere from 3 months to 1-2 years.

The UCT Library (the exemplar being used in this paper) in 2014 did a mid-year analysis, accepting that the articles that have been supported via the APC project would not have reached the anticipated level of maturity to generate citations. A superficial analysis was done to try and identify citation trends. Using actual data supplied by BioMed Central, the Library interrogated the data to identify download and citation trends. Table 2 shows the number of downloads and citations generated over the short period of time (2012-2014). In the three year period, UCT paid APCs for 60 BioMed Central articles which generated 140 citations. In 2012, one of the articles generated 17 citations. In 2014, in less than six months, one of the articles had already generated three citations. The authors use this evidence to corroborate the assertions made by Harnad and Brody [22] and Koler-Povh, Turk, and Južni [23].

The authors are of the opinion that the movement towards open access necessitates a change in mindset and that institutional libraries should have, as a line item, a budget for open access support. The fact that only three institutions in South Africa currently support APCs means the leadership in 
academic libraries needs to come to grips with the changing publication fee model influencing the open access movement.

Table 2. Impact of APC funding.

\begin{tabular}{ccccc}
\hline Year & No of Articles & $\begin{array}{c}\text { Total No. of } \\
\text { Downloads }\end{array}$ & $\begin{array}{c}\text { Total No. } \\
\text { of Citations }\end{array}$ & $\begin{array}{c}\text { Most No. of } \\
\text { Citations Per Article }\end{array}$ \\
\hline 2012 & 11 & 34543 & 71 & 17 \\
2013 & 19 & 62272 & 60 & 6 \\
2014 & 30 & 36896 & 9 & 3 \\
\hline
\end{tabular}

By the same token, the authors are cognizant of the fact that some institutions are spending up to $5 \%$ of their total journal acquisition budget on APCs, making APCs unsustainable. Further, some institutions are facing a potential increase in their journal subscriptions budget of up to $45 \%$ due to the "at source" increase and the devaluation of the South African rand (currency), compounded by the recent mandatory implementation of $14 \%$ value added tax on electronic resources. In the current economic climate this is not affordable. It is acknowledged that this will be a major strain, demanding a revisit on the affordability of APCs. In essence, APCs will be sacrificed in lieu of the continuation of subscription to journals.

The authors are caught in the dilemma of supporting APCs in a period where current austerity measures are hampering research activities in South African institutions of higher education.

\subsubsection{Library as Publisher}

There are four South African higher education libraries that offer a hosting (or acting as publisher) open access journals service. This new service is aligned to the assertions made by Skinner et al. [24] who point out that academic and research libraries are increasingly assuming the role of publisher. This role is usually inspired by campus-based demands for digital publishing platforms to support ejournals and conference proceedings. Although publishing is compatible with librarians' traditional strengths, there are additional skill sets that library publishers must master in order to provide robust publishing services to their academic communities. In the South African academic libraries publishing environment, the software that is being used to provide this publishing service is Open Journal Systems (OJS). As indicated by Skinner et al. [24], new skills are necessary to provide this service. In 2010, Stellenbosch University, in collaboration with UNESCO, facilitated a training workshop that was delivered by the creators of the OJS software (Public Knowledge Project (PKP)). This was the beginning of the capacity building exercise in South Africa.

Subsequent to the training, Stellenbosch University had taken the lead and began carving a path for the use of OJS - three other institutions followed in the footsteps of Stellenbosch University. In October 2011, Stellenbosch University launched SUNJournals via the library. This publishing platform currently hosts 20 journal titles. Some of the titles that SUNJournals hosts appear on the DHeT list of accredited journals, mentioned earlier.

Part of the suite of services provided by Stellenbosch University Library, in terms of "the library as publisher", is the distribution of unique Digital Object Identifiers (DOIs). As a registered member of CrossRef, an international DOI registration agency, the Library has the capacity to assign a DOI to 
each article. The DOI ensures authenticity, which reinforces the trustworthiness of the journal title. Further, CrossRef also ensures that the DOIs are harvestable by leading harvesting institutions [25].

Although OJS has subscription capabilities, Stellenbosch University adopted the fundamental principle that the content be made openly accessible to the world's research population and society at large. It subscribes to the common belief that research be made available as a public good. Further, Stellenbosch University was also pursuing the postulation [26-28] that open access radically improves the visibility of research content. The positive spinoffs of this improved visibility is the capacity to attract funds (including research funds), attract students of high caliber (including international students), and attract collaboration with the best researchers at national and international levels. Essentially, increased visibility means increased prestige for the institution and all other advances that go with it.

The University of South Africa publishes five titles via OJS. These titles are:

Journal of Philosophy in Schools;

International Journal for Educational Integrity;

The Journal of Educational Enquiry;

The Journal of Student Wellbeing; and

Teaching and Learning in (Higher) Education for Sessional Staff.

The University of the Western Cape publishes two titles using OJS. These are Critical Studies in Teaching and Learning and Journal of Student Affairs in Africa.

The University of Cape Town has begun its OJS journey with the publication of an undergraduate journal UR@UCT: undergraduate research. As a research intensive institution, UCT's ambition is to increase the number of postgraduate students through the growth of the pipeline of undergraduate students. The University pursues the principle that research begins at the undergraduate level and hence the objective of this journal is to give undergraduate students an opportunity to get published.

Further, the creation of UR@UCT: undergraduate research provides a conduit to showcase scholarly output from undergraduate students. The journal is also meant to encourage and explore intellectual capabilities beyond the classroom and provide a forum for the exchange of research ideas. Publishing research as an undergraduate provides a bridge between knowledge and experience. The opportunity to publish in a journal allows undergraduates to explore creating new knowledge and career opportunities in the academic world.

Open Monograph Press

The University of Cape Town is currently experimenting with the possibility of publishing monographs in an open access forum. Currently, academics at the University are placing their unpublished monographs on their websites for use by fellow researchers and practitioners. The possibility of using Open Monograph Press (OMP) to convert the websites into published monographs has become a distinct reality and is being currently piloted.

The pilot is guided by the announcement by Willinsky [29] that the OMP software platform is available for use to manage the editorial workflow required for the publication of monographs, edited volumes, and other scholarly editions. The workflow allows for internal and external reviewing and 
editing. In using open source software, the system is freely available to the academic community, and designed to reduce clerical costs and supplies, as well as overhead, with libraries becoming involved in hosting the system and scholars being able to play a more active role as series editors in the review process. The title that is being piloted for publication by UCT Library using OMP is The quest for $a$ deeper meaning of research support.

\subsection{Open Educational Resources}

Vijay Kumar [30] points out that the paucity of high-quality educators, inadequate infrastructure for delivering educational resources including libraries, and overall the poor quality of educational resources utilized at the various universities and colleges is a major challenge in the developing world. In South Africa this is exacerbated by what Modisaotsile [31] describes as a "crisis in basic education" (p. 1). The majority of the learners that pass matriculation (year 12) do not meet the minimum requirements for university entrance. Spaull [32] posits that "the South African education system is grossly inefficient, severely underperforming, and egregiously unfair" (p. 3). The graduation rate of those that enter universities is $15 \%$ [33]. As much as it is suggested that there are a myriad of reasons for this low graduation rate, the authors maintain that a significant contributing factor is the "underpreparedness" of the students when they articulate from school to university.

Vijay Kumar [30] goes on to state that a deprivation of quality education infringes on a fundamental human right. Quality education promotes individual freedom and empowerment and yields important development benefits; hence, the advocacy of the basic philosophy of OERs, which is to provide a more homogeneous quality of education, universally. Today, tremendous disparity exists in education due to the uneven availability of quality educational resources and infrastructure.

Given this basic philosophy, the authors subscribe to the UNESCO definition of OERs, which states that everyone should have the freedom to use, customize, improve, and redistribute educational resources without constraint. OERs must be used to improve teaching and learning and to widen access to higher education [34]. The singular purpose of OERs, as per UNESCO's definition, is the sharing of educational resources purely for developmental purposes.

As much as OERs are associated with the developing world, Niko and Armellini [35] assert that the UK government views OER as an instrument, in its social inclusion agenda, for widening learners' access to higher education. The Indian government [30] advances that our success in the knowledge economy hinges to a large extent on upgrading the quality of, and enhancing the access to, education. One of the most effective ways of achieving this would be to stimulate the development and dissemination of quality Open Access (OA) materials and Open Educational Resources (OER) (p. 78).

OERs have a significant role to play in leveling the education playing field in both the developed north and the developing south. However, the need is far more acute in the developing south. Despite the authors' bias for the UNESCO purpose of OERs, the reality is that there are two key drivers behind the motive for sharing teaching and learning materials; namely, an improvement in the quality of teaching and learning, and marketing and public relations. The latter motive negates the fundamental principles of open scholarship which is the sharing of resources as a public good. 


\subsubsection{Benefits of OERs}

OERs help improve education across the globe, especially in developing countries where many students cannot afford to buy textbooks, where access to classrooms may be limited, and where teacher-training programs may be lacking. They are also important in wealthy industrialized countries, where they can offer significant cost savings. For students, OERs offer free access to potentially some of the world's best courses and even degree programs. They can also offer huge cost savings as an alternative to expensive textbooks. For teachers, ministries of education, and governments, OERs provide free and legal access to some of the world's best courses. Educators can then adapt them to local languages and cultures and use them as a basis for innovation. According to Hylén [36] you do not have to be a teacher or a student to understand the importance of OERs. Free information is a fundamental human right, and OERs make it possible for people of all ages and backgrounds to learn more about the world around them and to access the tools they need to improve their lives and livelihoods.

The authors believe that OERs are the most challenging aspect of open scholarship as academics place their content in an open forum purely for development purposes: without any materialistic reward, including the lack of citation count. The views of the authors are in alignment with that of Taylor [37] who moots the fact that the lack of a rewards system should be countered by giving recognition to the creator of a learning resource. Despite the philanthropic underpinning of OERs, it is criticized, in the current state of development, for the one directional flow from the global north to the global south. Kanwar, Kodhandaraman, and Umar [38] go on to state that this presents the danger that a potentially important development is perceived as a manifestation of neo-colonialism before it has had a chance to embed itself in Africa and other developing countries.

\subsubsection{MOOCs}

Massive open online courses (MOOCs) are defined as free, OA, and scalable online higher education courses. The term was coined in 2008 to describe a particular model of open online courses developed by two Canadian academics (Downes and Siemens) [39]. The original aim of MOOCs was to open up education and provide free access to university level education for as many students as possible. In contrast to traditional university online courses, MOOCs have two key features. Firstly, they are open access, which allows participation by anyone in an online course for free. The second feature is that of scalability; that is, the courses are designed to support an indefinite number of participants. The development of MOOCs is rooted within the ideals of openness in education, that knowledge should be shared freely, and the desire to learn should be met without demographic, economic, and geographical constraints [39]. The promise that MOOCs brought was free access to cutting edge courses that could drive down the cost of university-level education. This has encouraged elite universities to put their courses online by setting up open learning platforms. However, new commercial start-ups, such as Coursera and Udacity, have brought a fee component, that is, charging a fee to the participants for certification.

Siemens [40] (one of the originators of MOOCs) articulates his concern in terms of the direction MOOCs have taken, stating that the new cohort of MOOCs are distinct from the original, in that they 
are "open" in only one respect, and that is open enrollment (p. 1). New [41] advances this concern suggesting, on the basis of a study conducted, that many universities use MOOCs as a marketing tool, that is, to increase the visibility of the institution and to drive student recruitment.

The authors align themselves with the concerns of Siemens [40] and New [41] with regard to the direction in which MOOCs have grown. The authors strongly believe that MOOCs have veered in its growth. Hence they are supportive of the view that OERs must remain focused on creating a ubiquitous global educational environment for open content, freely accessible to anyone, anytime, anywhere, and through any of the diverse computing and mobile technology tools available.

\subsubsection{Open Educational Resources in South Africa}

As intimated earlier, the OA roadmap in South Africa is being designed with pockets of excellence that provide necessary guidance. South African academic institutions have done relatively well with regard to institutional repositories (green route). They are now in a phase of development where they are supporting gold open access publishing, including the diamond OA model. However, South African higher education institutions are not, in the view of the authors, doing all that well when it comes to OERs. It is understandable as they have "only" just crossed the institutional repositories hurdle and still need to come to grips with the gold open access model. Be that as it may, there are only two institutions in South Africa that may profess to be active contributors to the OER movement. The first of these two is the University of Cape Town and the second is the University of South Africa. However, the fundamental principle driving the OER agenda in each of these institutions is very different. In the latter, the guiding principle is one of marketing the institution and in the former the guiding principle is one of development (elaborated on below).

The authors have a strong bias towards development as it is one of the mechanisms to address the legacies of apartheid, one of which is the presence of relatively well-endowed historically advantaged higher education institutions. These institutions have relatively strong infrastructures, including highly qualified academics/researchers; hence their student throughput rate and publication output is higher, earning them larger subsidies from national government. On the other hand, there are those historically disadvantaged institutions with the legacy of poor infrastructure and relatively lowly qualified academics/researchers negatively affecting throughput rate, publication output and attraction of quality students. The end result is smaller subsidy earnings from government, thus relegating these institutions further down the spiral of being "bush" institutions, a concept popularized in apartheid times.

The use of OERs as a marketing tool does little to instill confidence in the authors of OERs who are attempting to level the higher education playing field within South Africa. The competition for students (both undergraduate and postgraduate), funding, collaboration and such, within the higher education environment becomes debilitating for those institutions that have been prejudiced by the apartheid system and have to now overcome the "sword of Damocles".

\section{OERs at UCT}

The "OER programme" at UCT was driven by its Centre for Educational Technology. The "open" project solicited funding from national and international sources to provide assistance to academics in converting content into OERs. The assistance centered on navigating open licenses and curating 
content. The project was also instrumental in developing a network of open "champions", that is, committed academics whose sharing practice often pre-dated the Internet. The project was also successful in developing a model of sharing scholarly "objects" rather than solely modules or coursework [42]. Currently, there are 442 teaching and learning items in the repository, OpenUCT.

Another significant OER project at UCT occurred in the Faculty of Health Sciences in 2009 with eight other international partners to form the African Health OER Network, co-facilitated by OER Africa and the University of Michigan. The network provided resources for the conversion of teaching resources to OERs. The OER health work within UCT continues to grow. Another smaller OER project at UCT has been the provision of grants for academics to "buy in" student help or other expertise in converting existing materials or creating new materials to share as OERs. These very small grants, of less than $\$ 1000$ USD each, proved to be an effective mechanism for converting resources to open licenses. With 64 grants being made in a three-year period (2012-2014), a large number of educators were able to share their teachings more widely than in just their lecture rooms [42].

One of the more recent initiatives has been "Research into OERs for Development". This initiative hosted by UCT's Center for Innovation on Learning and Teaching (CILT), was launched in 2013. The aim of the project is "to provide evidence-based research from a number of countries in South America, Sub-Saharan Africa, and Southeast Asia with the primary objective of improving educational policy, practice, and research in developing countries by better understanding the use and impact of OER" [43].

\section{OERs at UNISA}

In its Open Education Resources (OER) Strategy 2014-2016 [44] UNISA notes that many universities are sharing their educational resources under open licenses to promote their learning experience to prospective students. Open sharing of UNISA content will most certainly solicit significant publicity and interest and, as such, will function as a major marketing platform for UNISA as a university of choice (p. 4).

UNISA goes on to align its OER strategy with the development of a new business model to attract more students. The strategy document [44] states that sharing content via OERs will be a marketing drive for UNISA as a university of choice ... Evidence from institutions such as MIT and the Open University in the UK indicates clearly that providing open access to materials leads directly to higher rates of applications from prospective students..." (p. 7).

In summation of Section 5.3, Figure 4, generated from a review of the literature, shows that OERs are built on the broad base of philanthropic sharing while the broadest base for MOOCs is the marketing of the institution. The low point of OERs is the marketing of the institution while the low point of a MOOC is philanthropic sharing. Hence in the case of UCT and Unisa, while the former demonstrates a focus on the sharing of educational resources for the development of society, the latter uses OERs as a marketing tool. The authors are convinced that engaging the openness movement must be underpinned by a philanthropic ethos. 


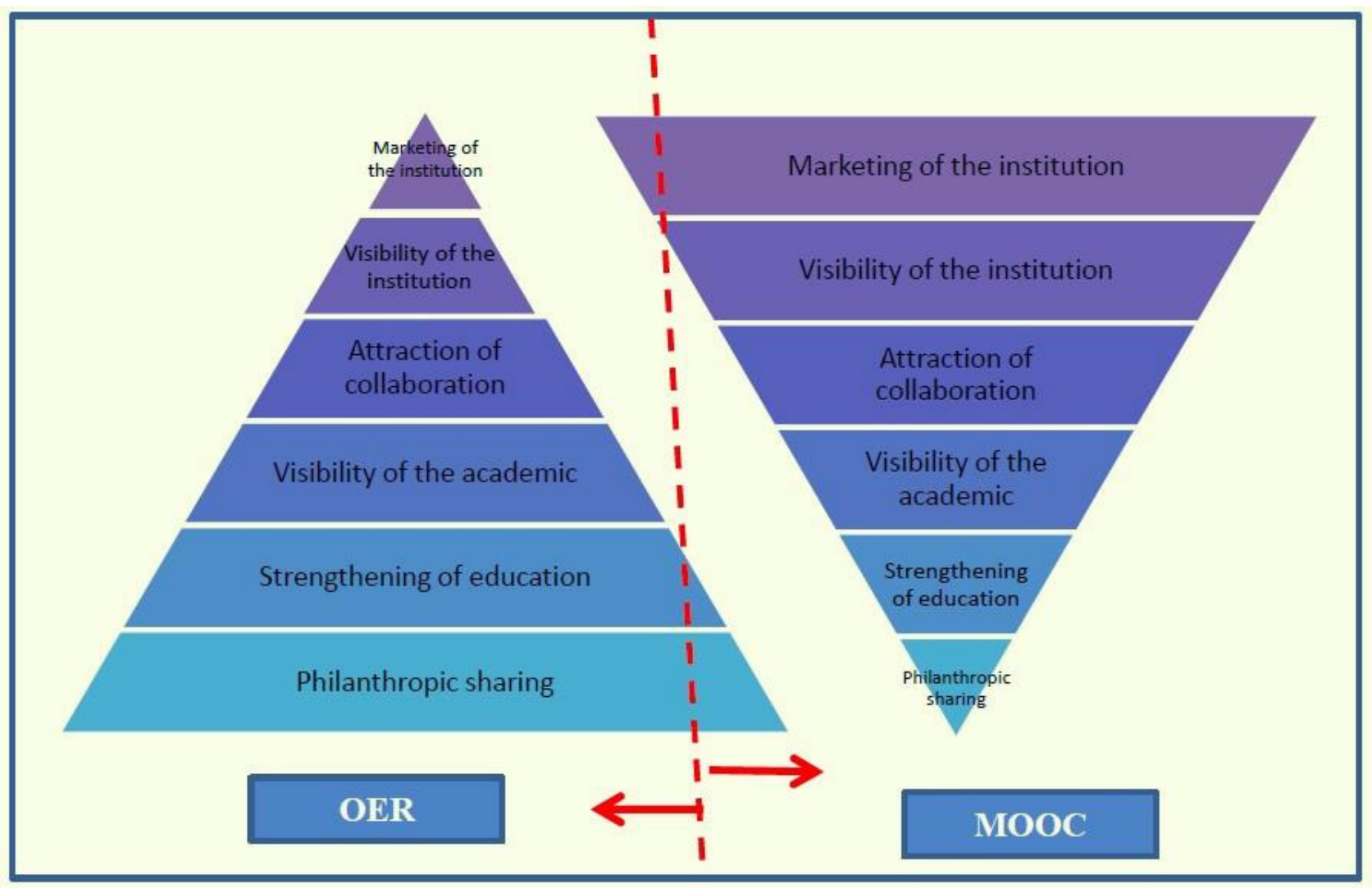

Figure 4. Comparison of fundamental purposes of OERs and MOOCs.

\subsection{Open Access and the National Research Foundation}

A new juncture in the South Africa OA roadmap is the open access statement from the National Research Foundation (NRF). The NRF is a state entity with the mandate to promote and support research through funding, human resource development, and the provision of the necessary research facilities in order to facilitate the creation of knowledge and innovation. According to the NRF's open access statement [45], "from 01 March 2015, authors of research papers generated from research either fully or partially funded by NRF, when submitting and publishing in academic journals, should deposit their final peer-reviewed manuscripts that have been accepted by the journals, to the administering Institution Repository with an embargo period of no more than 12 months" (p. 1). The NRF statement goes on to explain that earlier open access may be provided should this be allowed by the publisher. If the paper is published in an open access journal or the publisher allows the deposit of the published version in PDF format, such a version should be deposited into the administering institutional repository and open access should be provided as soon as possible. In addition, the data supporting the publication should be deposited in an accredited open access repository, with the provision of a Digital Object Identifier for future citation and referencing.

The higher education community in South Africa welcomes the NRF positon paper on open access. Notwithstanding this, higher education institutions in South Africa have indicated that this was long overdue. They have noted that the NRF is a publicly funded body and therefore has a moral obligation to society to ensure that public funded research is freely accessible to society. Hence, there is an expectation that such a funding body would be more robust or mandatory in its approach. Ideally, the 
NRF should have followed the precedent set by the National Institute of Health (USA) and Wellcome Trust (UK). These funding bodies have mandatory policies which give authors significant clout to challenge draconian publishing agreements. Authors and their respective institutions are armed by these funders with the necessary muscle to leverage waiver agreements from publishers to ensure that critical research output is freely accessible to society at large and to the entire research community. The NRF in South Africa should have adopted similar robustness in support of researchers and higher education in South Africa.

\section{Conclusions}

The substantial research output by South African institutions of higher education, especially the research intensive institutions, and their strong research and ICT infrastructure, have given their higher education libraries momentum to explore, adopt, adapt, and grow open scholarship practices. In pursuing the openness agenda, South African higher education institutions have been given the platform to share their research output to assist, inter alia, in leveling the higher education playing field, with historically disadvantaged institutions reaping the benefits of unhindered access to content that is published in institutional repositories and via gold open access forums. Institutions such as Stellenbosch University, University of the Western Cape, University of South Africa, and the University of Cape Town have gone as far as providing diamond open access services: a service that was not even on their horizons a few years back. The University of Cape Town is currently engaging with the Public Knowledge Project to pilot publishing open monographs (the diamond route). UCT has also led the country with the publishing of OERs.

South African higher education institutions, as a collective, have done well in embracing the open scholarship movement and in some instances are among the world leaders in the open scholarship arena. These institutions of higher education, over the last few years, have been constructing the open scholarship publishing roadmap. They have now developed the maturity and confidence to stake the claim that they are on the verge of converting the roadmap into a blueprint. Corroborating this elevated status is evidence that almost all of the South African institutions of higher education have an institutional repository, some institutions have budgets to support APCs, some of their libraries are acting as publishers and some are even providing "diamond gold" open access services.

The roadmap is being broadened to include Africa. The fact that South Africa has taken the leadership role for SPARC Africa (Scholarly Publishing and Academic Resources Coalition) augurs well for the growth of open scholarship in Africa as a whole. A continental open scholarship roadmap is being contemplated and developed.

\section{Author Contributions}

The authors, Reggie Raju, Jaya Raju and Jill Claassen, contributed equally to this paper, i.e., conceived, designed, analysed the data and wrote the paper.

\section{Conflicts of Interest}

The authors declare no conflict of interest. 


\section{References}

1. Dutch universities start their Elsevier boycott plan. Univers: The independent news website of Tilburg University. Available online: https://universonline.n1/2015/07/02/dutch-universitiesstarttheir-elsevier-boycott-plan (accessed on 2 July 2015).

2. Odlyzko, A. Open access, library and publisher competition, and the evolution of general commerce. Eval. Rev. 2015, 39, 130-163.

3. Van Noorden, R. Open access: The true cost of science publishing: Cheap open-access journals raise questions about the value publishers add for their money. Nature 2013, 495, 426-429. Available online: http://www.nature.com/polopoly_fs/1.12676!/menu/main/topColumns/ topLeftColumn/pdf/495426a.pdf (accessed on 19 November 2015).

4. Raju, R.; Raju, J.; Smith, I. South Africa: The role of open access in promoting local content, increasing its usage and impact and protecting it. In Learning from the BRICS: Open Access to Scientific Information in Emerging Countries; Schöpfel, J., Ed.; Litwin Books: Sacramento, CA, USA, 2015; pp. 159-189.

5. Raju, R. The future of Open Scholarship for research and teaching and learning. In Proceedings of the Seminar on Road to Promoting Open Access to Researchers in Academic Institutions, Nelson Mandela Metropolitan University, Port Elizabeth, South Africa, 27 July 2015.

6. Shockey, N. 16-Year Old Touts Role of Open Access in Break through Cancer Diagnostic: Interview of Jack Andraka by Dr. Francis Collins, Director of the NIH. SPARC. Available online: http:/www.sparc.arl.org/news/16-year-old-touts-role-open-access-breakthrough-cancerdiagnosticinterview-jack-andraka-dr (accessed on 10 September 2015).

7. Tise, E.R. Strengthening African higher education through the dissemination of research content: The role of the library. In Proceedings of the Association of African Universities - Conference of Rectors, Vice Chancellors \& Presidents of African Universities, Stellenbosch, South Africa, 30 May-3 June 2011.

8. De Villiers, P.; Steyn, G. Effect of changes in state funding of higher education on higher education output in South Africa: 1986-2007. Stellenbosch Economic Working Papers: 24/2008. Available online: http:/www.ekon.sun.ac.za/wpapers/2008/wp242008 (accessed on 1 August 2015).

9. QS Top Universities: Worldwide university rankings, guides \& events. 2015. Available online: http://www.topuniversities.com/universities/region/6/country/7/country/54 (accessed on 8 August 2015).

10. Department of Education, South Africa. A Programme for the Transformation of Higher Education: Education White Paper 3. General Notice 1196 of 1997. Pretoria, South Africa. 1997. Available online: http://www.che.ac.za/media_and_publications/legislation/education-whitepaper-3-programmetransformation-higher-education (accessed on 20 June 2015).

11. Raju, R.; Raju, Roy. The progression from repositories to institutional repositories: A comparative examination of repositories at the Durban University of Technology and Stellenbosch University. In Proceedings of the 1st International Conference on African Digital Libraries and Archives (ICADLA-1), United Nations Conference Centre (UNCC), Addis Ababa, Ethiopia, 24-26 June 2009. 
12. Bloom T.; Ganley E.; Winker M. Data Access for the Open Access Literature: PLOS's Data Policy. PLoS Biol. 2014, 12, e1001797, doi:10.1371/journal.pbio.1001797.

13. Clobridge, A. Open data: Shining a light on data management practices. Online Search. 2015, 39, 68-70.

14. Bertot, J.; Gorham, U.; Jaeger, P; Sarin, L.; Choi, H. Big data, open government and egovernment: Issues, policies and recommendations. Inf. Polity 2014, 19, 5-16.

15. Lynch, C.A. Institutional repositories: Essential infrastructure for scholarship in the digital age. ARL: Bimon. Rep. 2003, 3, 226. Available online: http://www.arl.org/resources/pubs/br/br226/ br226ir.shtml (accessed on 14 October 2010).

16. The Directory of Open Access Repositories-OpenDOAR. 2015. Available online: http://www.opendoar.org/ (accessed on 5 June 2015).

17. Crow, R. The case for institutional repositories: A SPARC position paper. 2002. Available online: http://www.sparc.arl.org/sites/default/files/media_files/instrepo.pdf (accessed on 3 March 2010).

18. Swan, A. What is new in Open Access. LIBER Q. 2006, 16. Available online: http://eprints.ecs.soton.ac.uk/13638/ (accessed on 20 August 2008).

19. Björk, B.-C. The hybrid model for open access publication of scholarly articles-A failed experiment? J. Am. Soc. Inf. Sci. Technol. 2012, 63, 1496-1504. Available online: http://onlinelibrary.wiley.com/doi/10.1002/asi.22709/epdf (accessed on 18 September 2015).

20. Fuchs, C.; Sandoval, M. The diamond model of open access publishing: Why policy makers, scholars, universities, libraries, labour unions and the publishing world need to take noncommercial, non-profit open access serious. Triple C 2013, 13, 428-443. Available online: file://C:/Users/user/Downloads/502-1866-1-PB.pdf (accessed on 8 August 2015).

21. Clobridge, A. Open access: Progress, possibilities, and the changing scholarly communications ecosystem. Online Search. 2014, 38, 1-5. Available online: http://www.infotoday.com/OnlineSearcher/Articles/InDepth-Reports/Open-AccessProgressPossibilities-and-the-Changing-Scholarly-Communications-Ecosystem-95162.shtml (accessed on 8 September 2015).

22. Harnad, S.; Brody, T. Comparing the impact of open access (OA) vs. non-OA articles in the same journals. D-Lib Mag. $\mathbf{2 0 0 4}, \quad 10 . \quad$ Available online: http://www.dlib.org/dlib/june04/harnad/06harnad.html (accessed on 8 September 2015).

23. Koler-Povh, T.; Turk, G.; Juzni, P. Does the open access business model have a significant impact on the citation of publications?: Case study in the field of civil engineering. J. Publ. Dev. Transit. Emerg. Ctries. 2012, doi:10.5937/BIOAC-68.

24. Skinner, K.; Lippincott, S.; Speer, J.; Walters, T. Library-as-publisher: Capacity building for the library publishing subfield. Educ. Train. 21st Century Publ. 2014, 17, doi:10.3998/3336451.0017.207.

25. Raju, R.; Smith, I.; Talliard, P.; Gibson, H. Open access: Are we there yet?-The case of Stellenbosch University, South Africa. S. Afr. J. Libr. Inf. Sci. Spec. (Open Access) Launch Issue 2012, 1-19, doi:10.7553/80-229.

26. Swan, A.; Carr, L. Institutions, Their Repositories and the Web. 2008, 34, 31. Available online: http://www.sciencedirect.com.ez.sun.ac.za/science (accessed on 24 October 2011). 
27. Bevan, S.J. Developing an institutional repository: Cranfield QUEprints-A case study. OCLC Syst. Serv.: Int. Digit. Libr. Perspect. 2007, 23, 170-182. Available online: http://www.emeraldinsight.com/1065-075X.htm (accessed on 21 June 2009).

28. Greig, M.; Nixon, W.J. On the road to enlightenment: Establishing an institutional repository service for the University of Glasgow. OCLC Syst. Serv.: Int. Digit. Libr. Perspect. 2007, 23, 297-309. Available online: http://www.emeraldinsight.com/journals.htm?articleid=1622097\& show $=$ abstract (accessed on 4 August 2010).

29. Willinsky, J. Toward the design of an open monograph press. J. Electron. Publ. 2009, 12, doi:10.3998/3336451.0012.103. Available online: http://quod.lib.umich.edu/j/jep/3336451.0012.103? view=text;rgn=main (accessed on 24 September 2015).

30. Vijay Kumar, M.S. Open educational resources in India's national development. Open Learn.: J. Open Distance e-Learn. 2009, 24, 77-84, doi:10.1080/02680510802627860.

31. Modisaotsile, B.M. The Failing Standard of Basic Education in South Africa. Africa Institute of South Africa Briefing No. 72. 2012, 72. Available online: http://www.ai.org.za/wpcontent/uploads/downloads/2012/03/No.-72.The-Failing-Standard-of-Basic-Education-in-SouthAfrica1.pdf (accessed on 31 July 2015).

32. Spaull, N. South Africa's education crisis: The quality of education in South Africa 1994-2011. Report Commissioned by CDE. 2013, 1-65. Available online: http://www.section27.org.za/wpcontent/uploads/2013/10/Spaull-2013-CDE-report-SouthAfricas-Education-Crisis.pdf (accessed on 31 July 2015).

33. Mtshali, N. Only $15 \%$ of SA university students graduate. 2013. Available online: http://www.iol.co.za/lifestyle/family/kids/only-15-of-sa-university-students-graduate1.1531809\#.VksXFNIrLIU (accessed on 31 July 2015).

34. UNESCO. Open educational resources. Available online: http://www.unesco.org/new/en/ communication-and-information/access-to-knowledge/openeducational-resources/ (accessed on 16 June 2015).

35. Niko, S.; Armellini, A. The OER mix in higher education: Purpose, process, product, and policy Open and Distance Learning Association of Australia, Inc. 2012, 33, doi:10.1080/01587919.2012.697439.

36. Hylén, J. Open Educational Resources: Opportunities and Challenges; OECD's Centre for Educational Research and Innovation: Paris, France, 2006. Available online: http://www.oecd.org/edu/ceri (accessed on 2 November 2014).

37. Taylor, P. Quality and web-based learning objects: Towards a more constructive dialogue, in quality conversations. In Proceedings of the 25th HERDSA Annual Conference, Perth, Western Australia, July 2002. $7-10$ Available online: http://www.herdsa.org.au/wpcontent/uploads/conference/ 2002/papers/TaylorP.pdf (accessed on 6 November 2014).

38. Kanwar, A.; Kodhandaraman, B.; Umar, A. If content is king, why are OERs still uncrowned?: A developing world perspective. In Proceedings of the at 6th Pan-Commonwealth Forum on Open Learning, Le Meridien, Kochi, India, 24-28 November 2009. Available online: http://wikieducator.org/images/a/a7/Asha_Kanwar.pdf (accessed on 6 November 2014). 
39. Yuan, L.; Powell, S. Moocs and open education: Implications for higher education: A white paper. JISC/CETIS 2013. Available online: http://publications.cetis.ac.uk/2013/667 (accessed on 6 November 2014).

40. Siemens, G. How MOOCs are derailing open education: George Siemens' ICDE world conference keynote. International Council for Open and Distance Education, news archive, pt. 3. 2013. Available online: http://www.icde.org/en/icde_news/news_archive/2013/2013_part_3/How + MOOCs+are +derailing+Open+Education $\% 3 \mathrm{~A}+$ George + Siemens + ICDE + World + Conference + keynote .b7C_wJLMZ1.ips (accessed on 4 November 2014).

41. New, J. MOOCs: Nothing but a marketing tool? eCampus News, 20 January 2014. Available online: http://www.ecampusnews.com/top-news/moocs-marketing-015 (accessed on 3 November 2014).

42. Czerniewicz, L.; Cox, G.; Hodgkinson-Williams, C.; Willmers, M. Open education and the open scholarship agenda: A University of Cape Town perspective. 2014. Available online http://open.uct.ac.za/handle/11427/7497 (accessed on 10 November 2014).

43. Walji, S. Researching OER in Africa and the global South. University World News, 2014, 19 September, Issue $\quad$ No: $335 . \quad$ Available online: http://www.universityworldnews.com/article.php?story= 20140917111818454 (accessed on 8 September 2015).

44. De Hart, K. Unisa: Open education resources (OER) strategy 2014-2016. 2014. Available online: http://www.unisa.ac.za/contents/unisaopen/docs/OER-Strategy-March-2014.pdf (accessed on 16 June 2015).

45. National Research Foundation. 2015. Statement on open access to research publications from National Research Foundation (NRF)_Funded research. Available online: http://www.nrf.ac.za/sites/default/files/documents/oastatement_2015.pdf (accessed on 16 June 2015).

(C) 2015 by the authors; licensee MDPI, Basel, Switzerland. This article is an open access article distributed under the terms and conditions of the Creative Commons Attribution license (http://creativecommons.org/licenses/by/4.0/). 